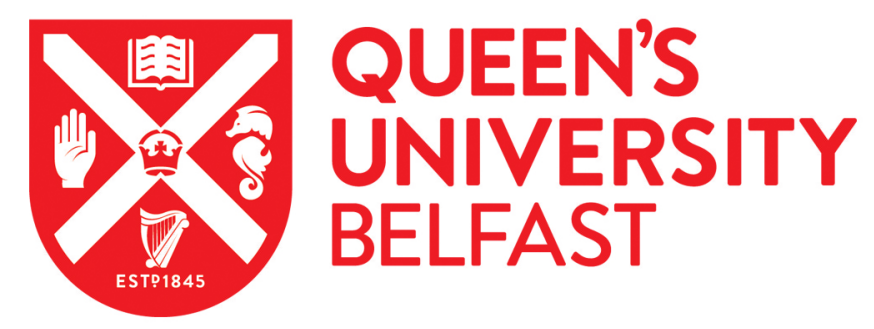

\title{
A Tool for Performance Evaluation of MPPT Algorithms for Photovoltaic Systems
}

Soulatiantork, P., Cristaldi, L., Faifer, M., Laurano, C., Ottoboni, R., \& Toscani, S. (2018). A Tool for Performance Evaluation of MPPT Algorithms for Photovoltaic Systems. Measurement: Journal of the International Measurement Confederation, 128, 537-544. https://doi.org/10.1016/j.measurement.2018.07.005

Published in:

Measurement: Journal of the International Measurement Confederation

Document Version:

Peer reviewed version

Queen's University Belfast - Research Portal:

Link to publication record in Queen's University Belfast Research Portal

Publisher rights

Copyright 2018 Elsevier. This manuscript is distributed under a Creative Commons Attribution-NonCommercial-NoDerivs License (https://creativecommons.org/licenses/by-nc-nd/4.0/), which permits distribution and reproduction for non-commercial purposes, provided the author and source are cited.

\section{General rights}

Copyright for the publications made accessible via the Queen's University Belfast Research Portal is retained by the author(s) and / or other copyright owners and it is a condition of accessing these publications that users recognise and abide by the legal requirements associated with these rights.

Take down policy

The Research Portal is Queen's institutional repository that provides access to Queen's research output. Every effort has been made to ensure that content in the Research Portal does not infringe any person's rights, or applicable UK laws. If you discover content in the Research Portal that you believe breaches copyright or violates any law, please contact openaccess@qub.ac.uk. 


\title{
A Tool for Performance Evaluation of MPPT Algorithms for Photovoltaic Systems
}

\author{
P. Soulatiantork, L. Cristaldi, M. Faifer, C. Laurano, R. Ottoboni, S. Toscani
}

\begin{abstract}
The use of photovoltaic (PV) systems as electrical power generator is increasing rapidly and this growth is expected to be continuous. As well known in PV systems the tracking of the maximum power point (MPP) is fundamental. For this reason, many testing systems and maximum power point tracking (MPPT) algorithms have been developed. Testing systems are used for the development as well as for assessing the quality of PV products. The typical problem related to the evaluation of PV system performances and MPPT algorithm comparison is the guarantee of the repeatability of the testing conditions (e.g. temperature and radiation).

In this paper, a testing system for PV applications has been developed and characterized. Flexibility, ease of use, low cost, capability to evaluate the characteristic curves of more than one PV panel simultaneously (same environmental conditions), the capability of algorithms simulation, and capability of tracking MPP on the base of different MPPT algorithms are some of the main characteristics. Experimental tests have been carried out to show the capability of the developed architecture. Different MPPT algorithms have been compared in the same environmental conditions both in the steady and dynamic state.
\end{abstract}

Index Terms- Maximum power point trackers, Photovoltaic systems, Solar panels, PV testing systems.

\section{INTRODUCTION}

A mong all renewable technologies, Photovoltaic (PV) energy is considered as the future of sustainable energy generation in many countries. More efficient and saving PV components and devices have been introduced making this technology more and more valuable. As well known the problem of finding and tracking the maximum power point (MPP) is vital for this kind of system. To fulfil this task, many maximum power point tracking (MPPT) algorithms have been developed. The testing of the devices and algorithms is a very important activity not only for PV system development but also for the quality verification of the products on the market. The main issue for the experimental testing is the need of guarantee environmental condition repeatability since, as well known, the PV cell performance strongly depends on solar radiation and temperature. The definition of current-voltage $(I-V)$ curves in different environmental conditions, completely characterize a solar cell, module or array. Unfortunately, the knowledge of these curves is not sufficient to estimate the actual generated power of the panels in working condition. In fact, as well known, the production also depends on the employed MPPT.

The typical experimental characterization is based on the use of artificial sun emulators that are extremely expensive and suffer of issues related to dimension limits of the testable system [1]. In literature, different studies comparing MPPT algorithms and PV modules have been developed [2]-[10]. However, just a few works compare different algorithms or different PV panels at the same environmental conditions and are mainly based on simulations analysis without experimental evaluation [11] [12].

For this reason, a testing system for PV applications has been developed. The system has been designed according to the following constraints: flexibility, ease of use, low cost, capability to evaluate the characteristic curves of more than one PV panel simultaneously. Moreover, it is able to implement every desired algorithm, simply changing the tracking software.

The system is based on a board for control and measurement management, controllable from the Simulink environment by MathWorks@ and hosted on a PC. The system gives the capability to measure the characteristics curve of four different panels in the same environmental condition, as well as the radiation and their temperature. Moreover, it is possible to simulate and directly implement different MPPT algorithms so as to compare their performance in real-time. The computation capability of the developed system allows the implementation of even complex MPPTs algorithms.

The paper is organized as follows. Section II the state of the art in PV testing systems is presented. Section III describes the hardware platform used in this paper for the MPPT algorithms and PV panel comparison. The MPPT algorithms utilized in the paper are presented in section IV. Section V is dedicated to the performance evaluation and comparison of employed MPPT algorithms and finally, Section VI presents the main conclusions.

P. Soulatiantork, L. Cristaldi, M. Faifer, C. Laurano, R. Ottoboni, and S. Toscani are with the Dipartimento di Elettronica, Informazione e Bioingegneria, Politecnico di Milano, 20133 Milan, Italy (e-mail: payam.soulatiantork@polimi.it; loredana.cristaldi@polimi.it; marco.faifer@polimi.it; christian.laurano@polimi.it; roberto.ottoboni@polimi.it; sergio.toscani@polimi.it;). 


\section{Photovoltaic Testing Systems}

In literature, different methods to measure PV modules can be found. Basically, the common method is based on a load impedance that can change its value from zero to infinite, in order to trace the PV module characteristic curve from short-circuit to open circuit state. Generally, variable resistors are the most widely used device to evaluate the $I-V$ and $P$ - $V$ characteristic curves. In [13] a system has been designed to determine the $I-V$ characteristic curve of seven photovoltaic modules sequentially. This system is composed of an array of resistors to act as a load for the PV module that can be connected to the panel through dedicated switching. Different configurations allow the system to sweep the curve so as to evaluate short-circuit current $\left(I_{s c}\right)$ and open circuit voltage $\left(V_{o c}\right)$. Although this might be a low-cost method for low power systems, resistors for high power applications are hardly available and the system would not follow rapid change conditions due to its slow dynamics.

Another method is named the capacitive method, which is based on the use of a capacitor as a load. In [14] a capacitive load method using insulated gate bipolar transistors (IGBTs) is designed. The system has the capability of measuring a short circuit current up to $80 \mathrm{~A}$ and an open circuit voltage up to $800 \mathrm{~V}$. As the capacitor start charging, its voltage increases from zero to open-circuit voltage of the PV module. Therefore, by measuring the voltage and current during the transient, the photovoltaic module can be characterized. The evaluation of $I$ - $V$ curves of PV modules must be both reliable and repetitive. Therefore, highquality capacitors with low equivalent series resistance (ESR) are needed. On the other hand, in this configuration, the system dynamic is slowed down by the discharging time constant [14].

The electronic load method utilizes transistors as a load. By controlling the gate of power switches and by changing their duty cycle from zero to one, the switch acts as a variable resistor; therefore, the $I-V$ curve can be measured. In [15] a metal oxide field effect transistor (MOSFET) has been used. In order to handle high power, different MOSFETs can be put in a parallel configuration. Differently, in [16] the electronic load uses an analog converter (DAC) and a bipolar junction transistor (BJT) in order to change the load conditions of the PV module. Unfortunately, with this configuration the switches must dissipate the generated power. Therefore, this limits the applicability of this method to low power applications similarly to the variable resistor method.

Other solutions are based on the employment of DC-DC converters. DC-DC converters have the property to emulate a variable resistance by modifying their duty cycle thus allowing to obtain the $I-V$ curve with a high dynamic and for different power size. Furthermore, they can continuously operate around the maximum power point (MPP) of the PV modules under test, following the reference signal provided by MPP algorithms. The issue of the use of DC-DC converters in this application is given by the presence of current ripple due to the switching technique. Coupled inductors and interleaved DC-DC converters allow to reduce it [17] [18]. Among the different DC-DC converter configurations, Buck-Boost topology is the one that allows the whole sweep of the $I-V$ curve [19].

For all these reasons, the experimental test setup has been based on a DC-DC converter and, in particular, a single ended primary inductor converter (SEPIC) topology has been chosen since it allows a lower ripple in the current drown from the PV module.

\section{THE HARDWARE PLATFORM}

The hardware platform has been designed for integrating real-time measurement and control for characterizing PV modules and MPPT algorithms. The system is based on a dSPACE board and allows testing simultaneously up to four PV modules by measuring currents, voltages, solar radiation and PV module temperatures. The dSPACE system provides the capability to develop user-friendly control panels for online monitoring and supervision. The interface and programming have been developed in Simulink/MATLAB environment with the SimPower/ MATLAB toolbox and dSPACE RTI1104 (Real-Time Interface) block set libraries.

As shown in Fig. 1, voltage and current of each PV module are measured and sent to the control system, in which the algorithms are embedded. Each module can be controlled independently by controlling the duty cycle of the related power converter. The dSPACE RTI1104 data acquisition and control board has been used to acquire current and voltage measurements and to generate the PWM signal to send to the SEPIC's MOSFET gate. Module temperatures and solar radiation level are acquired through temperature sensors (PT100, characterized by an accuracy of $0.3{ }^{\circ} \mathrm{C}$ in the range -50 to $150^{\circ} \mathrm{C}$ ) fixed under the $\mathrm{PV}$ module and a $2^{\text {nd }}$ class pyranometer. Measured data are sent through a sensor interface module (ADAM 4000 modules) to dSPACE board. ADAM-4000 family is an intelligent interface for environmental sensors that allows interfacing sensors to PC through RS-485 and RS-232 communication protocol [20]. The required algorithms have been implemented in the Simulink environment and PI controllers have been used to control the power converters [21]-[22]. 


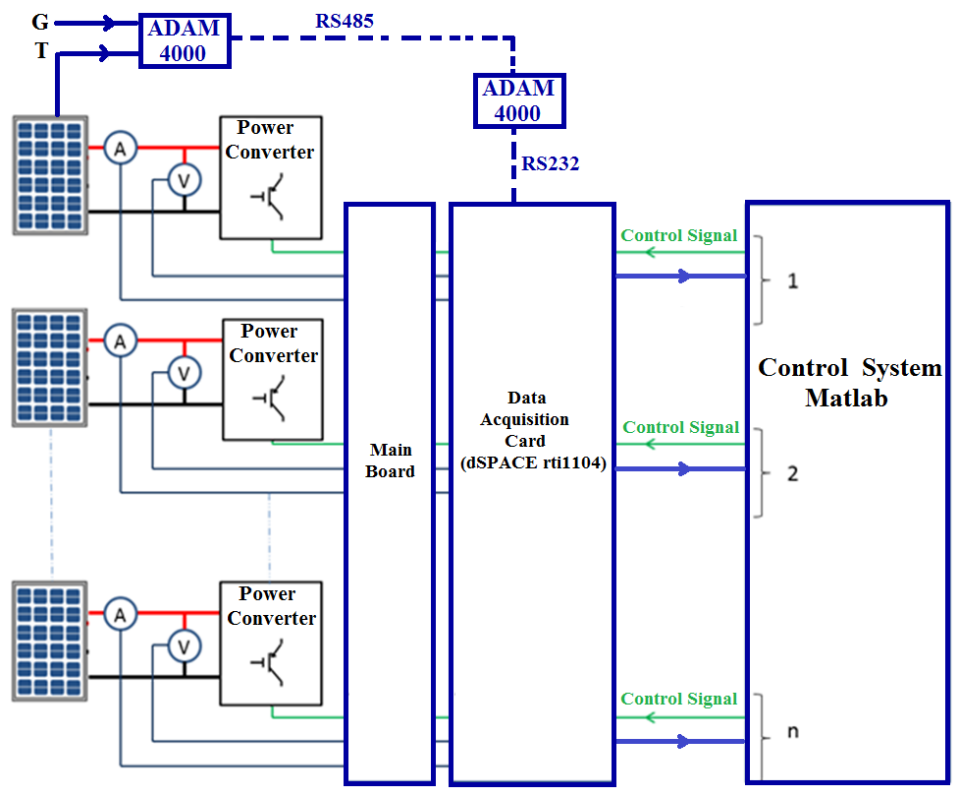

Fig. 1. Block diagram of the testing system for the PV modules.

SEPIC converter allows setting the working point of the PV module (Fig. 2). The converters have been designed in order to test PV modules featuring power up to $P_{\max }=200 \mathrm{~W}$, voltage up to $V_{\max }=100 \mathrm{~V}$ and currents up to $I_{\max }=6 \mathrm{~A}$.

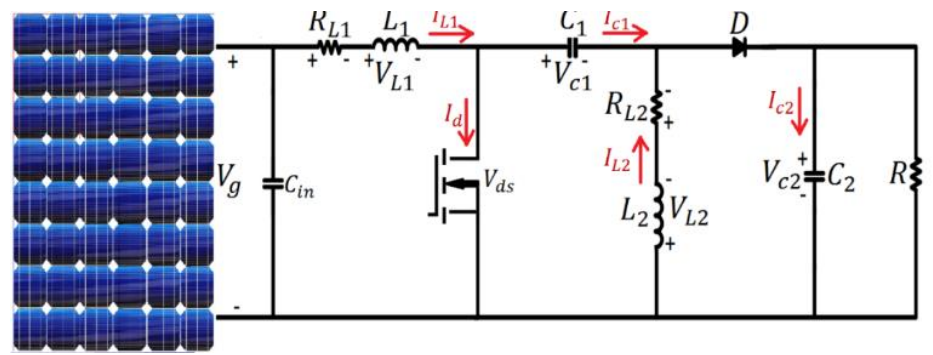

Fig. 2. SEPIC converter topology

Table I summarizes the electrical characteristics of the components employed in the power converters.

TABLE I .STANDARD COMPONENT ELECTRICAL CHARACTERISTICS

\begin{tabular}{ccc}
\hline Components & Characteristics & Total \\
\hline $\mathbf{L}_{\mathbf{1}}$ & $230 \mu \mathrm{H}, 5.5 \mathrm{~A}, 0.062 \Omega$ & $230 \mu \mathrm{H}$ \\
\hline $\mathbf{L}_{\mathbf{2}}$ & $230 \mu \mathrm{H}, 5.5 \mathrm{~A}, 0.062 \Omega$ & $230 \mu \mathrm{H}$ \\
\hline $\mathbf{C}_{\text {in }}$ & $100 \mu \mathrm{F}, 160 \mathrm{~V}$ & $100 \mu \mathrm{F}$ \\
\hline $\mathbf{C}_{\mathbf{1}}$ & $100 \mu \mathrm{F}, 160 \mathrm{~V}$ & $300 \mu \mathrm{F}$ \\
\hline $\mathbf{C}_{\mathbf{2}}$ & $470 \mu \mathrm{F}, 100 \mathrm{~V}$ & $940 \mu \mathrm{F}$ \\
\hline $\mathbf{D}$ & $200 \mathrm{~V}, 10 \mathrm{~A}, 1.1 \mathrm{~V}$ & -- \\
\hline Mosfet & $250 \mathrm{~V}, 94 \mathrm{~A}, 0.085 \Omega$ & -- \\
\hline
\end{tabular}

Resistive voltage dividers are employed to measure the converter input and output voltages. The transducer signal is sent through a voltage follower and a low pass filter to the ADC of the dSPACE rti1104 board. The current generated by the PV module and the converter output currents are measured through LEM LTS-6NP current sensors. The sensor output voltage is low pass filtered and sent to the dSPACE ADC module. Fig. 3 shows the schematic of the developed SEPIC converter together with the current and voltage sensors. 


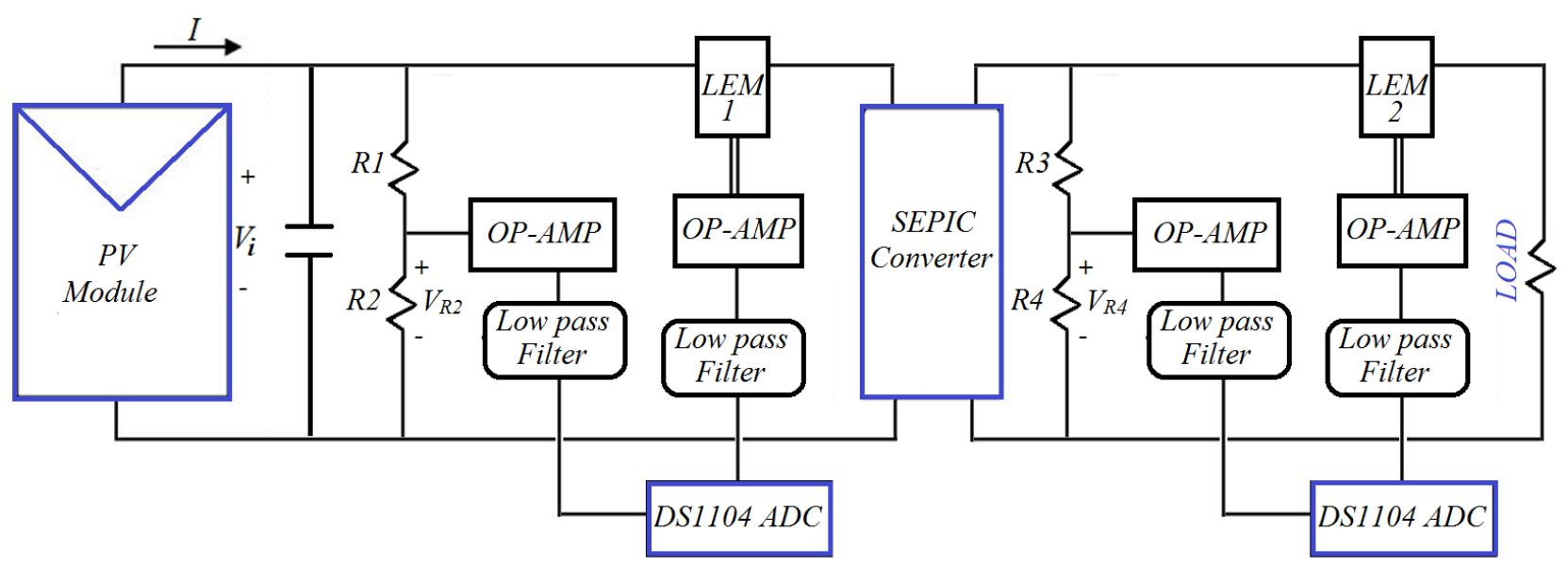

Fig. 3. Block diagram of the test setup: PV module, measurement devices and the SEPIC converter.

As shown in Fig. 3, two measurement sections have been implemented, respectively at the input and output of the power converter thus allowing also to perform evaluation of the converter efficiency [23]-[24]. The power converter boards are then hosted on the main board able to accommodate up to four SEPIC converters and providing the interface with the dSPACE system (Fig. 4).

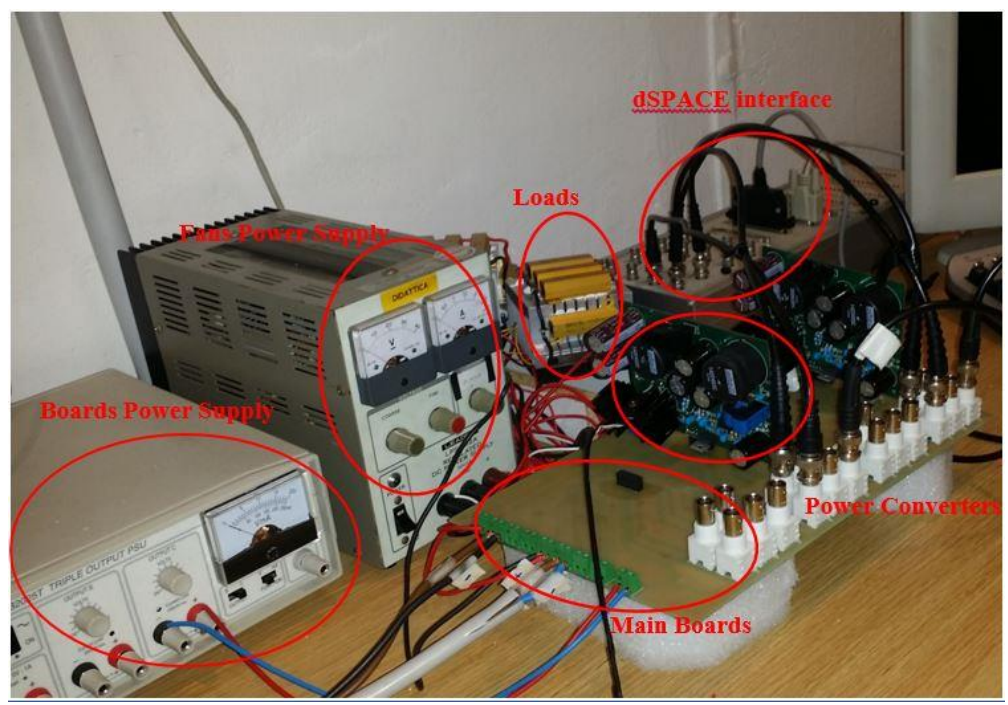

Fig. 4. Experimental setup: the main board, the SEPIC converters and boards supply are highlighted.

\section{A. Uncertainty evaluation}

In order to test different MPPT algorithms, the board metrological characteristics have to be determined. For this reason, a FLUKE 8845A multimeter has been employed for calibrating the measurement channels, including the whole measurement chain by comparing the board measurement with the multimeter. The relative uncertainty of the instrument is $0.005 \%$ and $0.05 \%$ for voltage and current measurement respectively (type B uncertainty). The relative measurement uncertainties of the developed system have been evaluated to be $0.1 \%$ for both voltage and current measurement respectively in the range of: $5 \mathrm{~V}$ to $50 \mathrm{~V}$ and 0.5 A to $6 \mathrm{~A}$.

Since voltage and current measurement uncertainty is mostly given by the transducers uncertainty, voltage and current measurement can be considered uncorrelated. Therefore, the relative uncertainty of the measured power comes simply from the uncertainty propagation law:

$$
u_{r}\left(P_{m}\right)=\sqrt{u_{r}^{2}\left(V_{m}\right)+u_{r}^{2}\left(I_{m}\right)}
$$

From equation (1), the relative uncertainty on the energy evaluation can be derived:

$$
u_{r}(E) \approx u_{r}\left(P_{m}\right)
$$

by considering the uncertainty on time negligible with respect to the power uncertainty. In fact, if the relative uncertainty on power is considered constant on the whole measurement range, the relative uncertainty on the energy evaluation is equal to the power uncertainty. 


\section{MPPT ALGORITHMS}

It is well known that the PV generated power strongly depends on the module temperature and solar radiation; hence, it changes during the day. MPPT algorithms must provide a very accurate MPP reference to the converter in terms of voltage $\left(V_{m p}\right)$ or current $\left(I_{m p}\right)$ in order to maximize the produced energy. For this reason, the module voltage (or current) must be controlled (usually through power converters) through algorithms that allow the module to work as close as possible to its maximum value. In the scientific literature, different techniques have been developed; some of them are based on the knowledge of the shape of the $I-V$ characteristic (hill-climbing methods), others are based on the PV module model. The board is able to implement each desired MPPT algorithm, modifying the control software; in particular, in this work two hill-climbing algorithms, the Perturb and Observe ( $\mathrm{P} \& \mathrm{O})$ and Incremental Conductance (IC) methods have been taken into account together with a model-based algorithm. In the following subsection, the three algorithms are presented.

\section{A. $P \& O$ algorithm}

The popular Perturb and Observe (P\&O) method is one of the most widely used MPPT algorithm, which does not require a priori knowledge of the $\mathrm{PV}$ module characteristics. There are different $\mathrm{P} \& \mathrm{O}$ algorithms among which the most popular are the reference current perturbation, the reference voltage perturbation and duty cycle perturbation [26]-[29]. Usually, the voltage dynamic is lower than that of the current, so the preferable method is the voltage perturbation one.

This technique operates by perturbing the voltage $V_{P V}$ of the PV module and comparing the power generated $\left(P_{P V}\right)$ before and after the perturbation. If the power increases by the changes in the PV voltage, the MPP has not been reached, and the voltage has to be increased again by adding a constant value called the 'step size' to the reference voltage. Otherwise, the MPP voltage is lower, and so the step size has to be subtracted.

The $\mathrm{P} \& \mathrm{O}$ algorithm flowchart used in this paper is depicted in Fig. 5. The choice of the step size $\Delta D$ and the perturbation time $T_{P}$ have been optimized according to the procedure reported in [30], depending on the measurement noise floor.

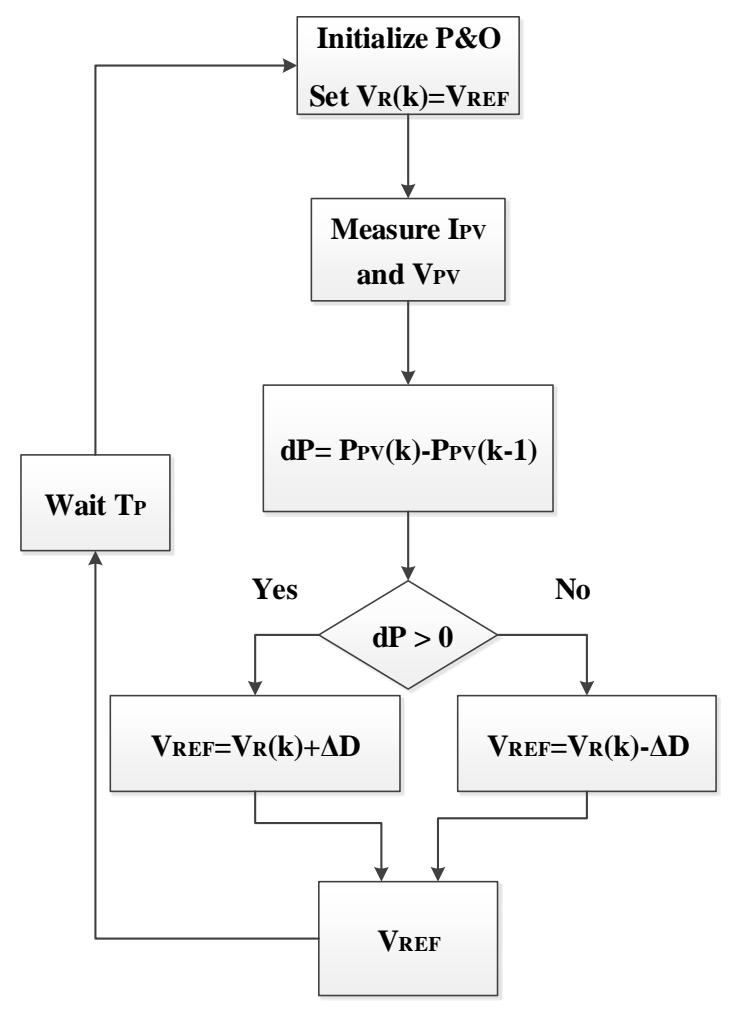

Fig. 5. P\&O flowchart diagram

\section{B. IC algorithm}

Incremental conductance (IC) method is another well-known hill climbing MPPT algorithm. This algorithm is based on the uniqueness of the MPP, which is a zero-derivative point in the $P-V$ plane [31] [32]. The algorithm is described in the flowchart of Fig. 6. 


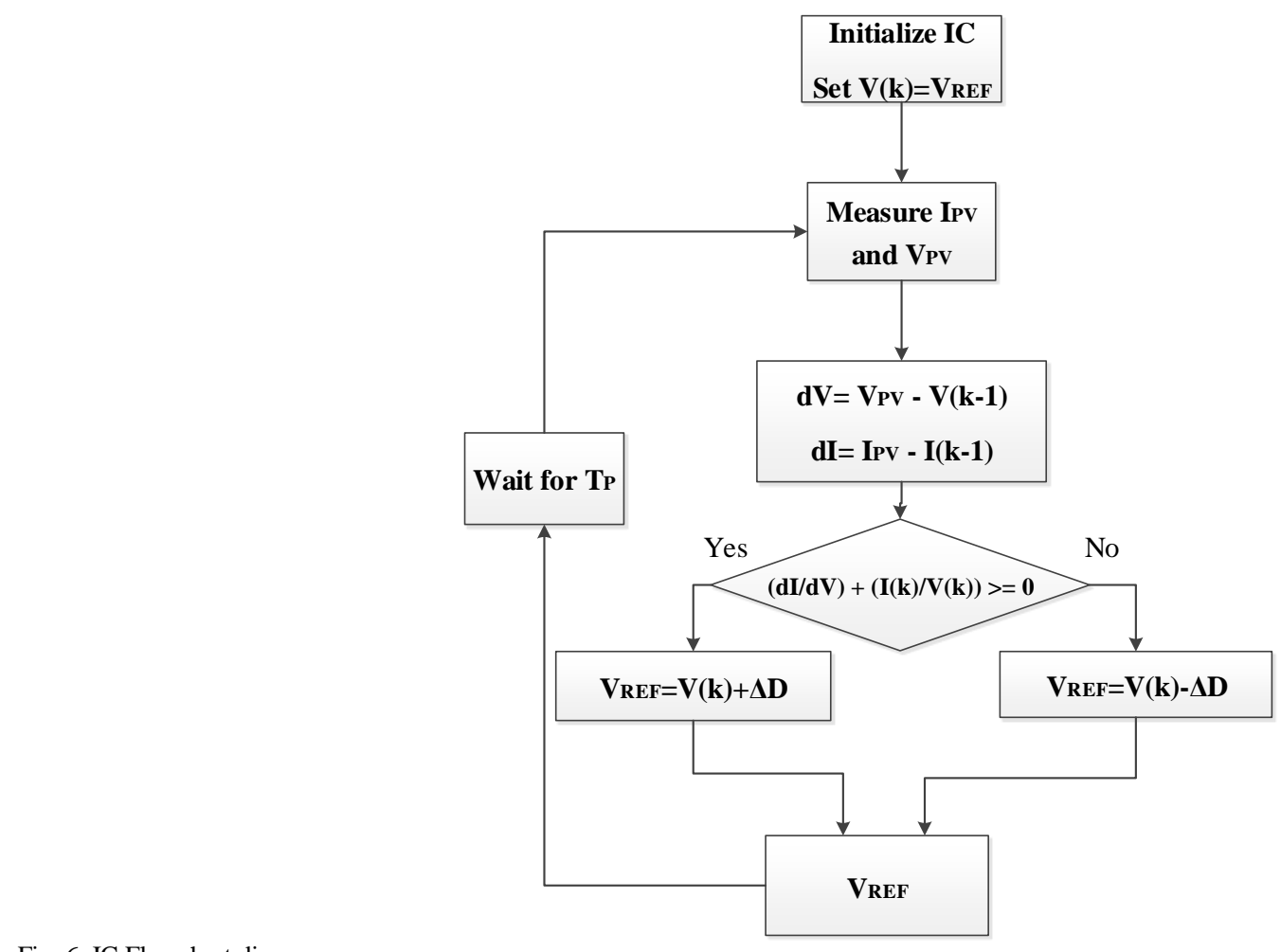

Fig. 6. IC Flowchart diagram.

The control strategy imposes to evaluate the derivative of the curve. If it is positive, the reference voltage $V_{R E F}$ applied to the module has to be increased; while a negative derivative means that the MPP is characterized by a lower voltage, and the step size must be subtracted. The problems relative to the choice of the step size and frequency are the same as for the previous method.

\section{Model-based algorithm}

Model Based (MB) MPPTs are designed to estimate the MPP by means of a PV model [33]. The main disadvantage of most MB MPPT methods is the necessity of measuring the solar radiation by a pyranometer, which could dramatically increase the cost of the system. Moreover, pyranometers have a very slow dynamic that results in a poor accuracy in the radiation measurement during variable cloudy days.

In recent works, the authors have proposed a MPP algorithm that is able to overcome the problem of the solar radiation measurement [34]-[36]. Starting from the assumption that the module MP current $I_{m p}$ is strongly dependent on the solar radiation [35], and quite proportional to it (while is poorly affected by the temperature) it can be written that

$$
\frac{I_{m p}}{I_{m p 0}} \cong \frac{G}{G_{0}}
$$

Where $I_{m p 0}$ and $G_{0}$ are the MPP current and the solar radiation in standard conditions. Therefore, the solar radiation $G$ can be indirectly obtained by measuring the maximum power point current $I_{m p}$. $V_{m p}$ can be estimated as:

$$
V_{m p} \cong V_{m p 0}\left[1+\beta_{m p}\left(T-T_{0}\right)+\delta_{1} \ln \left(\frac{I_{m p}}{I_{m p 0}}\right)+\delta_{2} \ln ^{2}\left(\frac{I_{m p}}{I_{m p 0}}\right)\right]
$$

As $I_{m p}$ is not known until the system is adjusted to operate at its MPP, equation (4) must be processed iteratively until convergence. It has been proved that replacing the MPP current with the measured current, the PV voltage converges to $V_{m p}$ [35]. The voltage reference to provide to the tracker at each iteration can be rewritten as:

$$
V_{r e f}=V_{m p} \cong V_{m p 0}\left[1+\beta_{m p}\left(T-T_{0}\right)+\delta_{1} \ln \left(\frac{I}{I_{m p 0}}\right)+\delta_{2} \ln ^{2}\left(\frac{I}{I_{m p 0}}\right)\right]
$$

In a simpler way, equation (5) can be written as:

$$
V_{\text {ref }}=V_{m p}=A_{0}+A_{1} T+A_{2} \ln (I)+A_{3} \ln ^{2}(I)
$$

$A_{0}$ to $A_{3}$ can be easily estimated by means of the Ordinary Least Squares method (linear regression) using a previously acquired set of $I-V$ curves. As demonstrated in [35], the algorithm converges in a very fast and accurate way. 


\section{PERFORMANCE EVALUATION AND COMPARISON OF MPPT ALGORITHMS}

In this section, a comparison among the MPPTs described in the previous section is reported in order to show the system capability in testing MPPT algorithms. In particular, the algorithms have been tested in both steady state and dynamic conditions. Then, the comparison in terms of generated energy has been performed.

In this work, three PV modules have been considered: a $180 \mathrm{~W}$ silicon monocrystalline module and two namely identical 80W polycrystalline solar modules (Table II).

TABLE II .PV MODULE PARAMETERS

\begin{tabular}{c|c|c}
\hline & $\mathbf{8 0 W}$ & $\mathbf{1 8 0 W}$ \\
\hline PV Parameters & Value & Value \\
\hline $\boldsymbol{V}_{\boldsymbol{o c}}$ & $21.33 \mathrm{~V}$ & $44.2 \mathrm{~V}$ \\
\hline $\boldsymbol{I}_{\boldsymbol{s} \boldsymbol{c}}$ & $5.03 \mathrm{~A}$ & $5.24 \mathrm{~A}$ \\
\hline
\end{tabular}

\section{A. Steady state condition comparison}

In order to evaluate the performance of the algorithms in steady-state conditions, the developed system has been used running sequentially the three previously presented algorithms. In particular, the test has been performed on the $180 \mathrm{~W}$ module. The system starts operating from the open circuit condition, tracking the MPP at $0.5 \mathrm{~s}$ applying MB algorithm. After other $500 \mathrm{~ms}$, time sufficient to guarantee the algorithm convergence, the $\mathrm{P} \& \mathrm{O}$ algorithm is applied (Fig. 7). As the $\mathrm{P} \& \mathrm{O}$ starting point is near the MPP, $500 \mathrm{~ms}$ is sufficient for the algorithm convergence. An MPPT frequency of $30 \mathrm{~Hz}$ and a voltage step of $0.5 \mathrm{~V}$ has been chosen for the $\mathrm{P} \& \mathrm{O}$ algorithm. After that, the characteristic curve is acquired by varying the load condition from open-circuit to short-circuit condition to evaluate the actual MPP values $I_{m p}$ and $V_{m p}$. The whole cycle lasts about 3 seconds. During that time, the temperature and solar radiation can be considered constant.

For the MB algorithm, the voltage and current are calculated by averaging the values (acquired with a sampling frequency of $10 \mathrm{kHz}$ ) in the time interval between $0.7 \mathrm{~s}$ and $0.95 \mathrm{~s}$ (Fig. 8). In Fig. 8, the voltage ripple of about $150 \mathrm{mV}$ of the converter can be seen. The voltage and current set by the $\mathrm{P} \& \mathrm{O}$ algorithm have been evaluated averaging the measured values between $1.2 \mathrm{~s}$ and $1.45 \mathrm{~s}$.

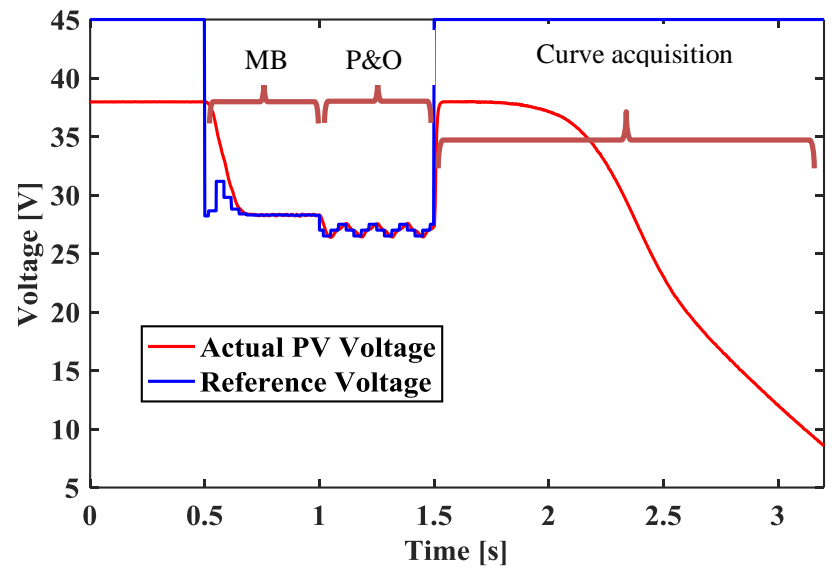

Fig. 7. MPPT algorithms steady state comparison strategy. 


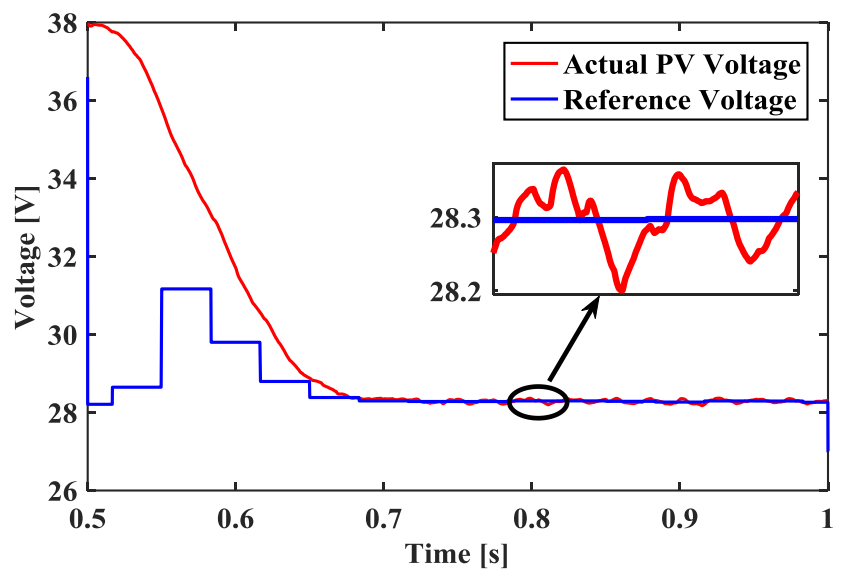

Fig. 8 Detail of MB MPPT during the tests.

The described procedure has been applied for two clear sunny days every $30 \mathrm{~s}$, with a minimum radiance threshold of 200 $\mathrm{W} / \mathrm{m}^{2}$. The power generated by the MB algorithm $\left(P_{M P_{-} M B}\right)$ and the P\&O MPPT $\left(P_{M P_{-} P \& O}\right)$ and the actual power extracted by the $I-V$ curve $\left(P_{M P, a}\right)$ have been compared (Fig. 9$)$ for each test cycle (\# of curve in figure).

To compare the performance of the algorithms in terms of energy loss, the energy efficiency $\eta_{M B}$ and $\eta_{P \& O}$ for the MB algorithm and the $\mathrm{P} \& \mathrm{O}$ one have been evaluated by applying the following equation:

$$
\eta_{A L G}=\frac{\sum_{n=1}^{N} P_{M P, a}-\sum_{n=1}^{N} P_{A L G}}{\sum_{n=1}^{N} P_{M P, a}}
$$

where $P_{A L G}$ is the power generated by the considered algorithm and $N$ the total number of curves.

It has been supposed that the power generated by each algorithm is constant between two different running of the same algorithm, hence the energy has been calculated as:

$$
E_{A L G}=\sum_{n=1}^{N} P_{A L G} \Delta t
$$

where $\Delta t$ is the difference between two convergence points, equal to $33.5 \mathrm{~s}$. Results are summarized in Table III. The relative uncertainty of the energy evaluation is equal to $0.14 \%$. The uncertainty of $\Delta E$ has been calculated by means of the uncertainty propagation law considering the two measurement uncorrelated. Actually, the uncertainty should be lower since the measured powers are highly correlated having used the same current and voltage measurement channels and being the measured values very close. Since the measurements of the powers are highly correlated, the uncertainty of $\Delta E$ should be computed considering a positive correlation coefficient, thus reducing the computed uncertainty.

Results show that the generated energy in steady state condition is basically the same for the two tested algorithms. Hence, the MB employment does not affect the energy losses due to the algorithm in a significant way with respect to the common hillclimbing methods. The same evaluation has been repeated for the comparison between the MB algorithm and the IC method. Results confirm the low discrepancy in terms of steady-state efficiency, which results in $98.6 \%$ and $98.2 \%$ for IC and MB algorithms respectively.

TABLE III. SUMMARY OF THE MB-P\&O PERFORMANCE COMPARISON

\begin{tabular}{cccc}
\multicolumn{4}{c}{ TABLE III. SUMMARY OF THE MB-P\&O PERFORMANCE COMPARISON } \\
\hline $\boldsymbol{E}_{\boldsymbol{a}}$ & Description & Value & Uncertainty \\
\hline $\boldsymbol{E}_{\boldsymbol{P} \& \boldsymbol{O}}$ & Sum of actual energy at MPP & $6180 \mathrm{~kJ}$ & $9 \mathrm{~kJ}$ \\
\hline $\boldsymbol{E}_{\boldsymbol{M B}}$ & Sum of P\&O estimated energy & $6100 \mathrm{~kJ}$ & $9 \mathrm{~kJ}$ \\
\hline $\boldsymbol{\Delta E}$ for P\&O & Sum of MB estimated energy & $6090 \mathrm{~kJ}$ & $9 \mathrm{~kJ}$ \\
\hline $\boldsymbol{\Delta E}$ for MB & Total generated energy difference for P\&O & $80 \mathrm{~kJ}$ & $13 \mathrm{~kJ}$ \\
\hline $\boldsymbol{\eta}_{\boldsymbol{P} \& \boldsymbol{O}}$ & Total generated energy difference for MB & $90 \mathrm{~kJ}$ & $13 \mathrm{~kJ}$ \\
\hline $\boldsymbol{\eta}_{\boldsymbol{M B}}$ & Generated Energy Efficiency for P\&O algorithm & $98.6 \%$ & \\
\hline & Generated Energy Efficiency for MB algorithm & $98.5 \%$ &
\end{tabular}




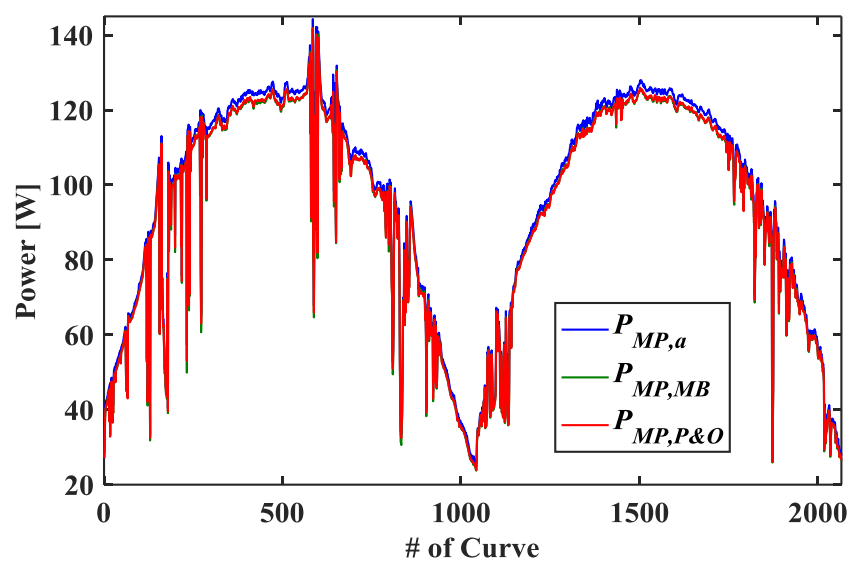

Fig. 9. Comparison between the different algorithms and the actual PV power reached during the observation period

\section{B. Dynamic performance comparison}

Once compared the steady-state performances of the three different MPPT algorithms, it is crucial to compare the dynamic performances of the algorithms. As the repeatability of the environmental conditions is impossible, the dynamic performance comparison can be evaluated during a completely sunny day, as for the steady state conditions. Given a wrong starting point to all the algorithms, the dynamic performances can be evaluated measuring the algorithms time response. 182 tests have been done by using an $80 \mathrm{~W}$ PV module. The voltage step and perturbation frequency have been set to $0.2 \mathrm{~V}$ and $30 \mathrm{~Hz}$ respectively.

The starting point of the reference voltage has been set wrongly to $17 \mathrm{~V}$, typical MPP voltage if cloudy conditions are considered. The algorithms have been run in sequence, with a pause of $0.5 \mathrm{~s}$ to set again the module voltage to $17 \mathrm{~V}$. Fig. 10 shows the generated power during one of the different tests. In the figure, it can be clearly noticed the higher speed of the MB algorithm compared to the others.

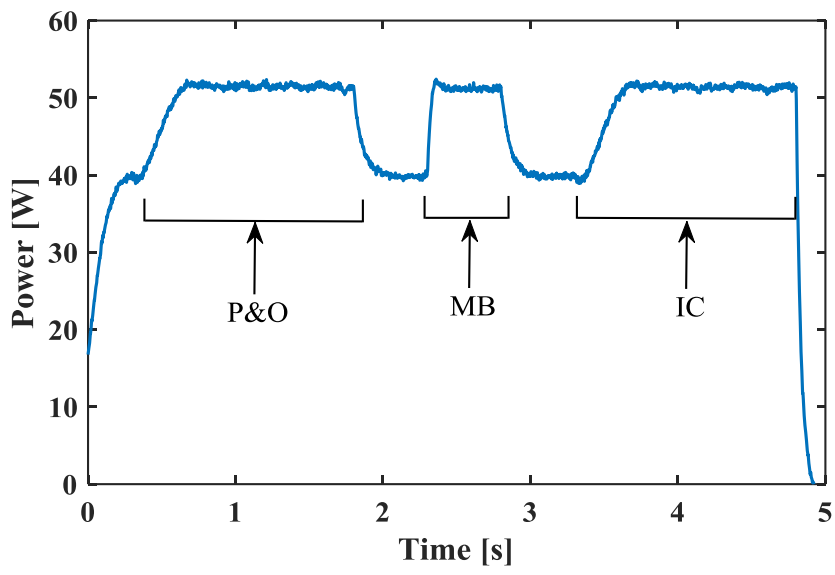

Fig. 10. The strategy of data collection for dynamic comparison.

Again, as the performance evaluation has been carried out during a completely sunny day, the environmental conditions have been assumed constant during the observation interval of $5 \mathrm{~s}$. The assumption has been verified comparing the steady-state powers reached by the three algorithms, comparable to the algorithm accuracy already presented in the previous subsection.

By aligning the starting points of each tracking algorithm, Fig. 10 can be replotted as shown in Fig. 11. From the figure, it is evident the different dynamic performance of the MPPTs. It is important to highlight that the main contribution to the limitation of the MB dynamic is given by the converter. On the contrary, the P\&O and IC methods are limited not only by the converter but from the number of the iterations needed to reach the steady state condition, higher than the ones needed by the MB MPPT. 

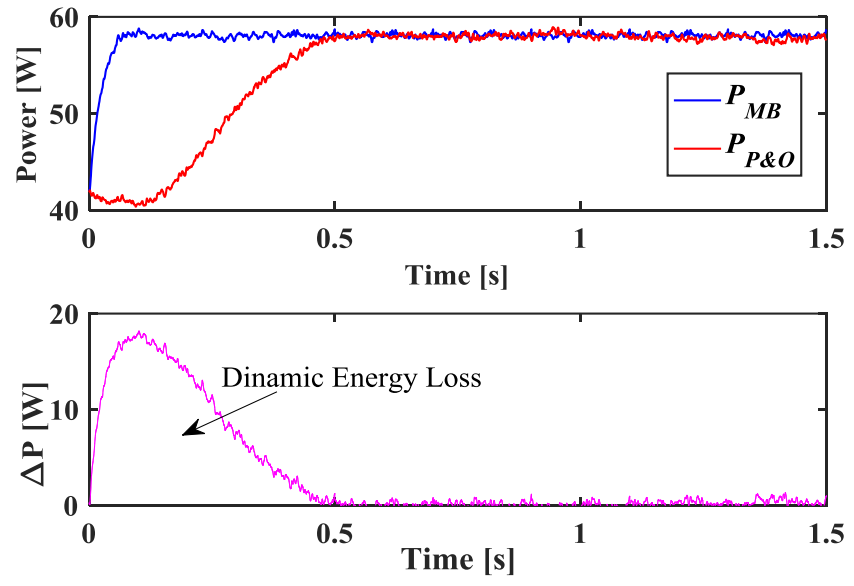

Fig. 11. Dynamic difference between $\mathrm{P} \& \mathrm{O}$ and $\mathrm{MB}$ algorithm and losses.

In order to give quantitative data, the dynamic energy losses can be computed. Given the MB algorithm as reference, the power difference between the MB algorithm and the hill-climbing algorithms over time have been computed as depicted in Fig. 11. In the figure, it can be distinguished the dynamic error and the steady state error. When the power difference is lower than $1 \mathrm{~W}$ (the error reaches approximately to $2 \%$ ), the system has been considered in steady state condition. Fig. 12 depicts the computed energy difference for both algorithms, while Fig. 13 reports the evaluation of the differences of convergence time of the two hill-climbing methods with respect to $\mathrm{MB}$ one.

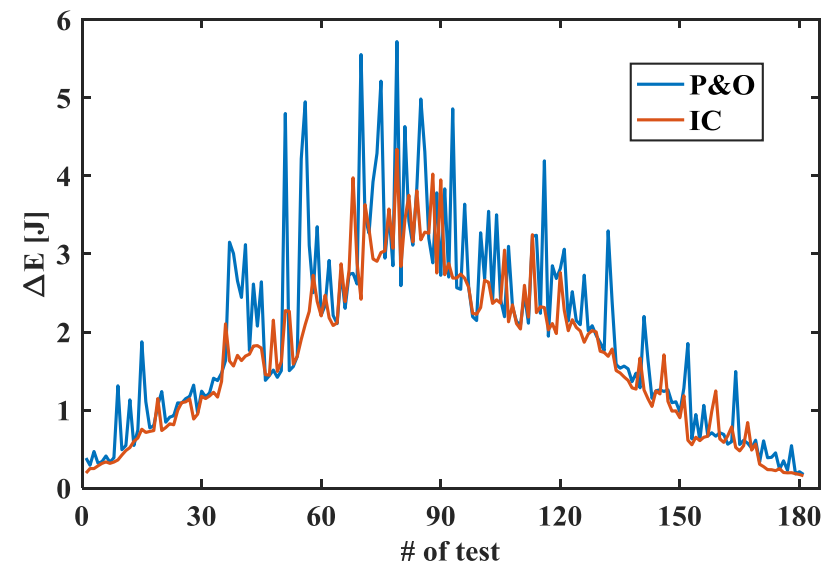

Fig. 12. MB-P\&O energy difference (Blue), MB-IC energy difference (Red)

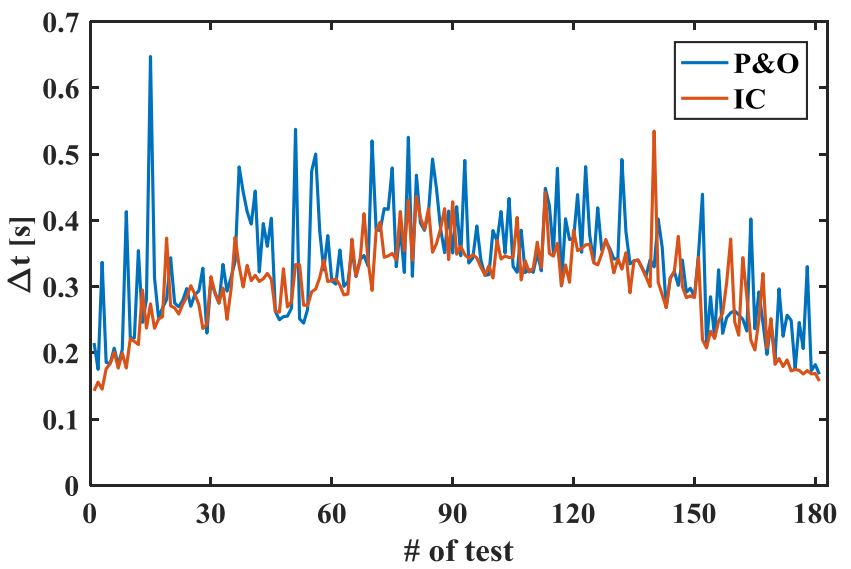

Fig. 13. Difference of time to steady state convergence for P\&O (Blue) and IC (Red) with respect to MB MPPT. 


\section{Real-time algorithm implementation}

The developed system allows testing different modules and algorithms at the same time. Real-time tests have been performed by using two PV modules featuring the same rated power ( $80 \mathrm{~W}$ rated power).

Firstly, a preliminary test has been carried out to evaluate the performances of the two modules. Therefore, the same MPPT algorithm has been run on both the modules simultaneously. From these tests, it has been proved that the first module (Module\#1) has a slightly higher power production if compared with Module\#2, around 2\% in terms of energy over a sunny day for radiation higher than $200 \mathrm{~W} / \mathrm{m}^{2}$.

Once having identified the differences between the two modules, MB and $\mathrm{P} \& \mathrm{O}$ algorithms have been used to track the MPP of the two panels in parallel for approximately 9 hours. $\mathrm{P} \& \mathrm{O}$ algorithm has been used to track Module\#1 MPP, while MB algorithm has been used to track Module\#2. The MPPT algorithm frequency was set to $30 \mathrm{~Hz}$ (Test \#1).

As expected, $\mathrm{P} \& \mathrm{O}$ algorithm performed better in higher radiations, as it was tracking the maximum power point of Module\#1. Conversely, in lower radiations and in sudden changes of the environmental condition, MB algorithm featured better performance; hence even if the MB algorithm has been implemented on the "weak" module, the high performances of the algorithm makes the energy produced by the two modules comparable to each other. Results are summarized in the first row of Table IV.

\begin{tabular}{cccccc} 
& \multicolumn{7}{c}{ TABLE IV SUMMARY OF RESULTS OF REAL-TIME TESTS } \\
\hline & $\begin{array}{c}\text { MB Energy } \\
(\mathbf{k J})\end{array}$ & $\begin{array}{c}\text { P\&O Energy } \\
(\mathbf{k J})\end{array}$ & $\begin{array}{c}\text { IC Energy } \\
(\mathbf{k J})\end{array}$ & $\begin{array}{c}\text { Difference } \\
(\mathbf{k J})\end{array}$ & $\begin{array}{c}\text { \% Difference } \\
\text { Uncertainty of } \\
\text { the difference } \\
(\mathbf{k J})\end{array}$ \\
\hline Test\#1 & 1490 & 1490 & -- & 0 & 3 \\
\hline Test\#2 & 1106 & 1072 & -- & 34 & $3.1 \%$ \\
\hline Test\#3 & 1262 & -- & 1260 & 2 & $0.16 \%$ \\
\hline Test\#4 & 1134 & -- & 1121 & 13 & 3 \\
\hline
\end{tabular}

In the second test (Test \#2) lasted 7 hours, the algorithms have been switched (MB for Module\#1, while P\&O has been used to track Module\#2). Now the difference of energy produced between the two algorithms is more relevant; this is simply explainable by the fact that the more efficient algorithm is now implemented to track the slightly better module. The energy generated by each algorithm is reported in the second row of Table IV.

The same tests have been carried out to compare the performances of the MB and IC algorithms (Test \#3 has been performed with the implementation of the IC MPPT to track Module\#1, while for the Test \#4 the two algorithms have been switched). Table IV summarizes the energy production of each algorithm in each test condition. Results are similar with respect to the first comparisons. Hence, it can be stated that in all cases the MB could force the system to produce more energy rather than conventional MPPT algorithms. This is mainly due to the different performance in variable environmental conditions.

\section{CONCLUSION}

This paper presents an experimental testing system allowing the comparison of different MPPT algorithms and PV modules simultaneously. The system is characterized by low cost (some $\mathrm{k} €$ ), high flexibility and proper accuracy for the testing of MPPT algorithms and PV modules. In fact, it allows to implement MPPT algorithms and testing them experimentally by using the same software environment. As shown in the paper, the system allows testing both steady-state and dynamic behaviour of different MPPT algorithms. P\&O, IC and MB algorithms have been tested, showing that the steady-state performances of the three algorithms are comparable while the efficiency of the MB algorithm in dynamic conditions is higher. Finally, a real-time comparison of the algorithms has been carried out showing the capability of the system of testing together different panels in real time.

\section{REFERENCES}

[1] D. S. Codd, A. Carlson, J. Rees, A. H. Slocum A low cost high flux solar simulator Solar Energy 84(2010) pp.2202-2212.

[2] T. Esram and P. L. Chapman, "Comparison of photovoltaic array maximum power point tracking techniques", IEEE Transactions on Energy Conversion, vol. 22, no. 2, June 2007, pp. 439-449.

[3] J. Lopez-Seguel, S. I. Jr. Seleme, P. Donoso-Garcia, L. F. Morais, P. Cortizo and M. S. Mendes, "Comparison of MPPT approaches in autonomous photovoltaic energy supply system using DSP”, IEEE ICIT, March 2010, pp. 1149-1154.

[4] M. A. G. de Brito, L. Galotto, L. P. Sampaio, G. A. Melo and C. A. Canesin "Evaluation of the Main MPPT Techniques for Photovoltaic Applications", IEEE Transactions on Industrial Electronics, vol. 60, no. 3, May 2012, pp. 1156-1167.

[5] A. D. Martin and J. R. Vazquez, "MPPT algorithms comparison in PV systems: P\&O, PI, neuro-fuzzy and backstepping controls," 2015 IEEE International Conference on Industrial Technology (ICIT), Seville, 2015, pp. 2841-2847.

[6] S. Ahmad, M. T. Rashid, C. S. Ferdowsy, S. Islam and A. H. Mahmood, "A technical comparison among different PV-MPPT algorithms to observe the effect of fast changing solar radiation,"2015 IEEE International WIE Conference on Electrical and Computer Engineering (WIECON-ECE), Dhaka, 2015, pp. 155-158.

[7] P. Soulatiantork, Performance comparison of a two PV module experimental setup using a modified MPPT algorithm under real outdoor conditions, Solar Energy, Volume 169, 15 July 2018, Pages 401-410

[8] Murtaza et al., "MPPT technique based on improved evaluation of photovoltaic parameters for uniformly irradiated photovoltaic array", Electric Power Systems Research 145, 2017. 
[9] Carullo et al., "Uncertainty analysis of degradation parameters estimated in long-term monitoring of photovoltaic plants", Measurement 55, 2014.

[10] Attivissimo et al., "On the performance of the double-diode model in estimating the maximum power point for different photovoltaic technologies", Measurement 46, 2013.

[11] C. Roncero-Clemente, O. Husev, V. Minambres-Marcos, S. Stepenko, E. Romero-Cadaval and D. Vinnikov, "Comparison of three MPPT algorithms for three-level neutral-point-clamped qz-source inverter," in Compatibility and Power Electronics (CPE), 2013 8th International Conference on, pp. 80-85, 2013.

[12] J. Chauhan, P. Chauhan, T. Maniar and A. Joshi, "Comparison of MPPT algorithms for DC-DC converters based photovoltaic systems," in Energy Efficient Technologies for Sustainability (ICEETS), 2013 International Conference on, pp. 476-481, 2013.

[13] E.E. van Dyk, A.R. Gxasheka, E.L. Meyer, "Monitoring current-voltage characteristics and energy output of silicon photovoltaic modules", Renewable Energy, Volume 30, Issue 3, March 2005, Pages 399-411,

[14] J. Munoz, E. Lorenzo, "Capacitive load based on IGBTs for on-site characterization of PV arrays ", Solar Energy, 80, 2006, pp. $1489-1497$.

[15] Y. Kuai, S. Yuvarajan, "An electronic load for testing photovoltaic panels", Journal of Power Sources, 154, 2006, pp. 308-313.

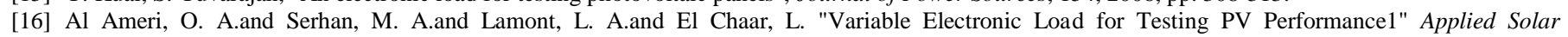
Energy,2010, Vol.46, pp. 89-96.

[17] J.M. Enrique, E. Duran, M. Sidrach-de-Cardona, J.M. Andujar, M.A. Boh6rquez, J.E. Carretero, "A new approach to obtain I-V and P-V curves of PV panels by using DC-DC converters", 31st IEEE PVSC, 2005, pp. 1769-1772.

[18] N. Lima Nelio, C.de Freitas, M.Gustavo, "Low Complexity System for Real-Time Determination of Current-Voltage Characteristic of PV modules and strings" Applied Power Electronics Conference and Exposition (APEC), 28th Annual IEEE, 17-21 March 2013 pp.2817-2823.

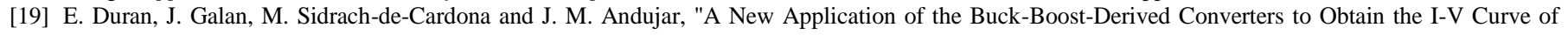
Photovoltaic Modules," 2007 IEEE Power Electronics Specialists Conference, Orlando, FL, 2007, pp. $413-417$.

[20] Adam-4000 series Data Acquisition Modules User's Manual.

[21] P. Solatian, S. Hamidreza Abbasi, and F. Shabaninia, "Simulation Study of Flow Control Based on PID ANFIS Controller for NonLinear Process Plants," Am. J. Intell. Syst., vol. 2, no. 5, pp. 104-110, 2012. http://dx.doi.org/10.5923/j.ajis.20120205.04.

[22] P. Soulatiantork, A. Alghassi, M.Faifer, S. Perinpanayagam, IGBT Thermal Stress Reduction Using Advance Control Strategy, Procedia CIRP, Volume 59, 2017, pp 274-279. http://dx.doi.org/10.1016/j.procir.2016.09.040.

[23] M. Faifer, L. Cristaldi, L. Piegari and P. Soulatiantork, "Design of a converter for photovoltaic panels testing," Clean Electrical Power (ICCEP), 2015 International Conference on, Taormina, 2015, pp. 674-681. doi: 10.1109/ICCEP.2015.7177564.

[24] M. Faifer, M. Khalil, L. Piegari, P. Soulatiantork, S. Toscani, " Improvement in the efficiency of DC-DC power converters by controlling the switching frequency," in proceeding of IMEKO TC10 Workshop on Technical Diagnostics, Advanced measurement tools in technical diagnostics for, systems' reliability and safety, Milan, Italy, June, 2016.

[25] R. Sankarganesh and S. Thangavel, "Maximum power point tracking in PV system using intelligence based P\&O technique and hybrid Cuk converter," Emerging Trends in Science, Engineering, and Technology (INCOSET), 2012 International Conference on, Tiruchirappalli, Tamilnadu, India, 2012, pp. 429-436.

[26] X. Liu, L.A.C. Lopes, "An improved perturbation and observation maximum power point tracking algorithm for PV arrays", in Power Electronics Specialists Conference, 2004, PESC 04. 2004, IEEE 35th Annual vol. 3, 2004, 2005-2010.

[27] R. Alonso, P. Ibanez, V. Martinez, E. Roman and A. Sanz, "An innovative perturb, observe and check algorithm for partially shaded PV systems," Power Electronics and Applications, 2009. EPE '09. 13th European Conference on, Barcelona, 2009, pp. 1-8.

[28] N. Femia, G. Petrone, G. Spagnuolo and M. Vitelli, "A Technique for Improving P\&O MPPT Performances of Double-Stage Grid-Connected Photovoltaic Systems," in IEEE Transactions on Industrial Electronics, vol. 56, no. 11, pp. 4473-4482, Nov. 2009.

[29] E. Koutroulis, K. Kalaitzakis and N. C. Voulgaris, "Development of a microcontroller-based, photovoltaic maximum power point tracking control system," in IEEE Transactions on Power Electronics, vol. 16, no. 1, pp. 46-54, Jan 2001.

[30] M. A. Elgendy, B. Zahawi and D. J. Atkinson, "Assessment of Perturb and Observe MPPT Algorithm Implementation Techniques for PV Pumping Applications," in IEEE Transactions on Sustainable Energy, vol. 3, no. 1, pp. 21-33, Jan. 2012.

[31] F. Liu, S.Duan, F. Liu, B. Liu, andY.Kang, "Avariable step size INC MPPT method for PV systems, " IEEE Trans. Ind. Electron., vol. 55, no. 7, pp. 26222628, Jul. 2008.

[32] A. Safari and S. Mekhilef, "Simulation and hardware implementation of incremental conductance MPPT with direct control method using cuk converter, " IEEE Trans. Ind. Electron., vol. 58, no. 4, pp. 1154-1161, Apr. 2011.

[33] L. Cristaldi, M. Faifer, M. Rossi, and S. Toscani, "A simplified model of a photovoltaic panel," in Proc. Int. Instrum. Meas. Technol. Conf., May 2012, pp. $431-436$.

[34] L. Cristaldi, M. Faifer, M. Rossi and S. Toscani, "An Improved Model-Based Maximum Power Point Tracker for Photovoltaic Panels," in IEEE Transactions on Instrumentation and Measurement, vol. 63, no. 1, pp. 63-71, Jan. 2014.

[35] M. Faifer, L. Cristaldi, S. Toscani, P. Soulantiantork and M. Rossi, "Iterative model-based Maximum Power Point Tracker for photovoltaic panels," 2015 IEEE International Instrumentation and Measurement Technology Conference (I2MTC) Proceedings, Pisa, 2015, pp. 1273-1278. doi: 10.1109/I2MTC.2015.7151456

[36] L. Cristaldi, M. Faifer, M. Rossi, S. Toscani. "A New Approach to Maximum Power Point Tracking for Photovoltaic Panels, " in Proc. IEEE Int. Conf. on Clean Electrical Power, Alghero, Italy, June 11-13, 2013, pp.461-465. 